\title{
GILLNET SELECTIVITY FOR THE NORTH AFRICAN CATFISH, CLARIAS GARIEPINUS (ACTINOPTERYGII: SILURIFORMES: CLARIIDAE), FROM THE UPPER OKAVANGO DELTA, BOTSWANA
}

\author{
Thethela BOKHUTLO ${ }^{*}$ and Ketlhatlogile MOSEPELE ${ }^{2}$ \\ ${ }^{1}$ Botswana International University of Science and Technology, Palapye, Botswana \\ ${ }^{2}$ Okavango Research Institute, University of Botswana, Maun, Botswana
}

Bokhutlo T., Mosepele K. 2015. Gillnet selectivity for the north African catfish, Clarias gariepinus (Actinopterygii: Siluriformes: Clariidae), from the Upper Okavango Delta, Botswana. Acta Ichthyol. Piscat. 45 (2): 133-141.

Background. Successful fisheries management requires estimation of gillnet selectivity for optimum exploitation of the resource. In the Okavango Delta, no study has assessed the selectivity of gillnets for Clarias gariepinus (Burchell, 1822) which is an important component of both the subsistence and the commercial gillnet fishery catch. The aim of this study was to simulate the harvesting pattern of the commercial gillnet fishery and provide gillnet selectivity parameters for C. gariepinus. This will help fishery managers with information on the appropriate mesh sizes needed for sustainable utilisation of the catfish resource.

Materials and methods. Monthly gillnet sampling was conducted over a period of 8 years from 2001 to 2009 . The SELECT method was used to estimate gillnet selectivity for C. gariepinus using catch data from four mesh sizes $(73 \mathrm{~mm}, 93 \mathrm{~mm}, 118 \mathrm{~mm}$, and $150 \mathrm{~mm})$.

Results. The $93 \mathrm{~mm}$ and $118 \mathrm{~mm}$ mesh sizes were the most efficient when capturing C. gariepinus accounting for $44.6 \%$ and $21.9 \%$ of the total catch, respectively. Mean fish length increased with increasing mesh size and was significantly different between mesh sizes $(P<0.001)$. The modal fish lengths for the four mesh sizes were estimated at $41.63 \mathrm{~cm}, 53.23 \mathrm{~cm}, 66.35 \mathrm{~cm}$, and $85.54 \mathrm{~cm}$ in order of increasing mesh size.

Conclusion. The modal fish lengths for meshes $93 \mathrm{~mm}$ and $118 \mathrm{~mm}$ are greater than the size at maturity and therefore the current commercial gillnet fishery which uses $100 \mathrm{~mm}$ mesh size may not be a threat to the C. gariepinus population in the Upper Okavango Delta. Future studies should aim to conduct fishery dependent selectivity studies in the lower Okavango Delta to determine if selectivity changes with location and gear. Moreover, a comprehensive age-based stock assessment is required to establish the mesh size that optimizes yield without adversely depleting the spawning stock biomass.

Keywords: growth, overfishing, mean length, mesh size, catch per unit effort, selectivity

\section{INTRODUCTION}

Recent studies have shown that even though gear selectivity is important in modern stock assessment, it is often poorly understood (Hulson and Hanselman 2014). Gillnets are the most preferred gear when harvesting fish from most parts of the world (Carlson and Cortés 2003), thus making it imperative to have adequate knowledge of their size selectivity so that sustainable yield may be maximized (Millar and Holst 1997). Indirect estimation of selectivity is the common method, used to estimate gillnet selectivity because direct estimation is difficult as it requires full knowledge of the species and size composition in the population (Hovgård et al. 1999).
Several studies have estimated gillnet selectivity parameters for various species around the world (Carlson and Cortés 2003, Dos Santos et al. 2003, Psuty et al. 2007, Baremore et al. 2012). However, they were not estimated for the North African catfish, Clarias gariepinus (Burchell, 1822), an important constituent of the subsistence and commercial gillnet fishery catch in the Okavango Delta (Van der Bank and Smit 2007, Mmopelwa et al. 2009).

Currently, the management strategy for the Okavango Delta fishery does not include mesh size regulation (Shipton unpublished $\left.{ }^{* *}\right)$. However, with foreseen rapid rate of increase in the human population growth in the Okavango

\footnotetext{
" Correspondence: Mr. Thethela Bokhutlo, Botswana International University of Science and Technology, Private Bag 16, Palapye, Botswana, phone: +2674900117 (office), +267 77131004 (cell), fax:+2674900102, e-mail: (TB) thethela.bokhutlo@gmail.com, bokhutlot@biust.ac.bw, (KM) kmosepele@ori.ub.bw.

** Shipton T.A. 2011. The Okavango Delta fisheries management plan. Support for Devising the Aquaculture Development Strategy for Botswana and the Development of outlines for the Fisheries Management Plan of the Okavango Delta. ACP Fish II Coordination Unit Service Contract No. CU/PEI/MZ/10/004.
} 
Delta (Anonymous unpublished*), pressure on the fishery resources may rise due to increased market demand. For this reason, the current management strategy may be inappropriate in the near future and it will be important to set exploitation guidelines that will ensure long-term biological and socio-economic sustainability of the resource (Richardson et al. 2009).

A good starting point in this endeavour is to determine gillnet selection patterns in the fishery because selectivity impacts considerably on the estimation of biological reference points and therefore has implications on management advice particularly in relation to harvest levels and stock status (Butterworth et al. 2014, Hulson and Hanselman 2014). Moreover, understanding selection patterns of gears is essential in age-structured stock assessment models (Carlson and Cortés 2003) and the results obtained from selectivity studies may assist fishery managers to predict the effect of proposed mesh size regulations on the catch size distributions (Dos Santos et al. 2003).

The aim of this study was to estimate gillnet selectivity parameters for Clarias gariepinus in the Okavango Delta using multi-panel gillnets of different mesh sizes that followed a similar pattern to those employed in the commercial gillnet fishery so that management interventions could be developed for this fishery.

\section{MATERIALS AND METHODS}

Study area. The Okavango Delta is a large inland wetland created by the Okavango River. The Delta is an alluvial fan covering almost $40000 \mathrm{~km}^{2}$ with a mean surface gradient of approximately $1: 3700$ in which the inflow of water and sediment from the Okavango River are spread across a meandering convoluted surface through a complex system of channels and floodplains (McCarthy et al. 1998). The Okavango Delta is one of Africa's most pristine Delta areas and it is rich in biodiversity with a large variety of habitats (Ramberg et al. 2006).

Data collection. Length frequency data were obtained through monthly gillnet sampling conducted over a period of 8 years from 2001 to 2009 . The gillnet fleet comprised 9 net panels made of nylon with different mesh sizes. These mesh sizes were $22 \mathrm{~mm}, 35 \mathrm{~mm}, 45 \mathrm{~mm}, 57 \mathrm{~mm}, 73 \mathrm{~mm}, 93 \mathrm{~mm}$, $118 \mathrm{~mm}$, and $150 \mathrm{~mm}$ stretched mesh. All panels were multifilament with a length of $10 \mathrm{~m}$ and a depth of $2.4 \mathrm{~m}$. Twine diameter was $210 \mathrm{D} / 4(0.56 \mathrm{~mm} \varphi)$ with a hanging ratio of $E$ $=0.5$. The panels were tied together in a random order and set monthly at Matsaudi Lagoon, Korao Lagoon, and Guma Lagoon (one overnight setting at each sampling station) (Fig. 1). Setting time was approximately $12 \mathrm{~h}$, from $1800 \mathrm{~h}$ to 0600 h. Fish were then removed from each panel and processed separately. Each fish was identified to species level, and then total length (TL) and the wet weight were determined.
Catch per unit effort. Catch per unit effort (CPUE) was calculated for each mesh size to determine the efficiency of each mesh size in capturing Clarias gariepinus. CPUE was calculated in Pasgear II (Kolding and Skaalvik ${ }^{* *}$ ) as:

$$
\mathrm{CPUE}=\frac{1}{y} \sum_{i=1}^{n} W_{i} \cdot \frac{\mathrm{SU}}{U_{i}} \cdot \frac{\mathrm{ST}}{T_{i}},
$$

where $y$ is the effort, e.g., number of net panels (or fleet) settings and $n=$ number of samples, $W_{i}=$ catch (in weight) in setting or sample $_{i}$, $\mathrm{SU}=$ standard relative effort unit (size) of a net panel, $U_{i}=$ actual effort (size) of net, $\mathrm{ST}=$ standard time unit ( $\mathrm{h}$ or min) of a setting, $T_{i}=$ actual time

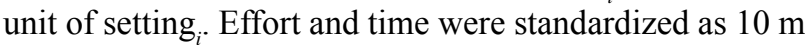
long net panels set over $12 \mathrm{~h}$.

Catch distributions. In order to evaluate the differences between size frequency distributions against meshes, the Kolmogorov-Smirnov goodness-of-fit test $(\mathrm{K}-\mathrm{S})$ for two samples was applied. Mean size between different combinations of net panels was compared using the multiple comparison of means Tukey test. Analyses were implemented in R using packages multcomp, FSA and pgirmess (Hothorn et al. 2008, Ogle ${ }^{* * *}$, Giraudoux ${ }^{* * * *}$ ).

Gillnet selectivity. For detailed analyses of gillnet selectivity, only mesh sizes from $73 \mathrm{~mm}$ to $150 \mathrm{~mm}$ were considered due to their relatively high efficiency in capturing Clarias gariepinus. Relative selection was used to estimate selectivity. The population of C. gariepinus was reconstructed by length and expected catches were compared against observed catches. To do this, catches were grouped by mesh size into $5 \mathrm{~cm}$ TL size bins, and the selectivity curve for each mesh size was calculated using the midpoint of each size class (Millar and Holst 1997). The SELECT method (Millar and Holst 1997, Millar and Fryer 1999) was used to fit four gillnet selectivity models to each mesh size. The models were fitted to data in R using the package gillnet functions (Millar ${ }^{* * * *}$ ). When using SELECT, maximum likelihood estimation is employed and selectivity parameters are estimated from a general log-linear model under the assumption that catches are Poisson random variables (Millar and Holst 1997, Millar and Fryer 1999).

The expected catch for Clarias gariepinus of length class $l$ in gillnet $j$ was expressed following Millar and Holst (1997) as:

$$
v_{l j}=p_{j} \lambda_{l} r_{j}(l)
$$

where $p_{j}$ is the relative fishing intensity of gillnet $j, \lambda_{l}$ is the abundance of catfish in length class $l$; and $r_{j}(l)$ is the selection curve for each gillnet $j$.

\footnotetext{
"Anonymous 2003. Ngamiland District Settlement Strategy (2003-2027). Plantec Africa (PTY) LTD., Lesedi Consulting Engineers (PTY) LTD. Ministry of Lands and Housing, Department of Town and Regional Planning, Northwest District Council, Tawana Land Board.

** Kolding J., Skaalevik A. 2010. Pasgear II. Version 2.1. A database program for experimental or artisanal fishery data. University of Bergen, Norway. Available at http:// www.imr.no/forskning/utviklingssamarbeid/eaf_nansen_proprammet/nansi s/pasgear_2/110222/en.

*** Ogle D.H. 2013. FSA: Fisheries stock analysis. R package version 0.3.5.

**** Giraudoux P. 2013. pgirmess: Data analysis in ecology. R package version 1.5.8. http://CRAN.R-project.org/package=pgirmess.

${ }^{* * * * * *}$ Millar R.B. 2011. Next generation R functions for trawl and net (or hook) selectivity. [http://www.stat.auckland.ac.nz/ millar/selectware/RNext/].
} 
The expected catch can be expressed in log-linear form such that:

$$
\begin{aligned}
\log \left(v_{l_{j}}\right)= & \log \left(p_{j}\right)+\log \left(\lambda_{l}\right)+\log \left(r_{j}(l)\right) \\
& =\sum_{i} \beta_{i} \cdot f_{i}(j, l)
\end{aligned}
$$

where $f_{i}(j, l)$ is a function of only $j$ and /or $l$. In this form, the maximum likelihood can easily be fitted using existing statistical software (Millar and Holst 1997).

Four models fitted to data were:

- Normal (with fixed spread);

- Normal (with spread proportional to mesh size);

- Lognormal, and

- Gamma.

The normal, gamma, and lognormal models observe geometric similarity, whereas the normal model with fixed spread is not geometrically similar (Millar and Fryer 1999). The models were fitted under the assumptions that catches were independent and that gillnet panels were fished with equal effort. For a detailed description of the selection equations and their assumptions see Millar and Holst 1997, and Millar and Fryer 1999.

To determine the maximum selected size or mode for each panel, the equations shown in Table 1 were used. Each model was fitted twice to estimate selectivity, first under the assumption that fishing intensity was equal among meshes and secondly under the assumption that fishing intensity was proportional to mesh size (Millar and Holst 1997). To test the models for overdispersion, the dispersion parameter was calculated by dividing the model deviance by the degrees of freedom. A dispersion parameter that is $>1$ implies that data are overdispersed (Millar and Fryer 1999).

\section{RESULTS}

CPUE and catch distributions. A total of 1046 Clarias gariepinus were caught during the sampling period. CPUE was low $\left(<0.2 \mathrm{~kg} \cdot \mathrm{panel}^{-1} \cdot \mathrm{set}^{-1}\right)$ for mesh sizes smaller than $57 \mathrm{~mm}$ (Fig. 2). From the $57 \mathrm{~mm}$ mesh size, CPUE increased with mesh size to a maximum of $1.5 \mathrm{~kg} \cdot$ panel $^{-1} \cdot \mathrm{set}^{-1}$ in the $93 \mathrm{~mm}$ mesh then decreased to $1.0 \mathrm{~kg} \cdot \mathrm{panel}^{-1} \cdot \mathrm{set}^{-1}$ in the $150 \mathrm{~mm}$ mesh size. The $93 \mathrm{~mm}$ and $118 \mathrm{~mm}$ mesh sizes were therefore considered most efficient. These mesh sizes accounted for $44.6 \%$ and 21.9 $\%$ of the total catch, respectively. The mean length of the captured C. gariepinus generally increased with increasing mesh size (Table 2). The comparison of mean length showed significant difference between different combinations of mesh sizes (Table 3 ). The catch size frequency distributions for different mesh sizes are shown in Fig. 3. The two sample Kolmogorov-Smirnov test showed significant differences between all catch size frequency distributions (Table 4).

Gillnet selectivity. The results for the fits of the four models are shown in Table 5. The normal model with fixed spread under the assumption that fishing intensity was proportional to mesh size gave the best fit. The assumptions of different fishing intensity did not affect the model deviances for the lognormal and the gamma models. The best model had a deviance of 238.94 on 52 degrees of freedom indicating overdispersion. This is shown by the pattern of the deviance residuals plot where all models were consistently biased with none demonstrating a distinct departure in the quality of fit to data (Fig. 4). Therefore these results do not confirm the assumption of independent catches for Clarias gariepinus. For mesh sizes 73 and $118 \mathrm{~mm}$, large negative residuals indicate that the observed catch was less than that predicted by the model for size classes

Table 1

Equations used to estimate the modal lengths of Clarias gariepinus collected from the upper Okavango River delta, Botswana, in each gillnet mesh size for the four selectivity models

\begin{tabular}{cc}
\hline Model & Mode \\
\hline Normal (fixed and proportional spread) & $m_{j=} \kappa \cdot m_{j}$ \\
Gamma & $m_{j}=(\alpha-1) \cdot \kappa \cdot m_{j}$ \\
Lognormal & $m_{j}=\exp \left(\mu-\sigma^{2}\right) \cdot\left(m_{j} \cdot m_{1}^{-1}\right)$ \\
\hline
\end{tabular}

$m_{j}=$ mesh size for panel $\mathrm{j} ; \kappa, \alpha, \mu, \sigma$ are the maximum likelihood parameter estimates derived from log-linear fits of SELECT.

Table 2

Principal morphometric characteristics of Clarias gariepinus collected from the upper Okavango River delta, Botswana and their relation to the mesh size of the net used

\begin{tabular}{cccc}
\hline \multirow{2}{*}{ Mesh size $[\mathrm{mm}]$} & $n$ & Mean \pm SD & Total length $[\mathrm{cm}]$ \\
\cline { 3 - 4 } & & $45.70 \pm 7.13$ & $24-71$ \\
\hline 73 & 191 & $49.62 \pm 6.56$ & $17-80$ \\
93 & 466 & $60.50 \pm 6.40$ & $28-84$ \\
118 & 229 & $74.75 \pm 11.38$ & $45-106$ \\
\hline
\end{tabular}

$n=$ number of fish collected, $\mathrm{SD}=$ standard deviation. 
Table 3

Results of the Tukey contrasts for the multiple comparisons between different mesh sizes used and the mean length of the captured Clarias gariepinus from the upper Okavango River delta, Botswana

\begin{tabular}{cccccc}
\hline Mesh size $[\mathrm{mm}]$ & Estimate & SE & $95 \%$ LCI & $95 \%$ UCI & $P$-value \\
\hline 150 vs. 118 & 14.25 & 0.95 & 11.83 & 16.67 & $<0.0001$ \\
73 vs. 118 & -14.80 & 0.70 & -16.58 & -13.01 & $<0.0001$ \\
93 vs. 118 & -10.88 & 0.58 & -12.35 & -9.41 & $<0.0001$ \\
73 vs. 150 & -29.05 & 0.97 & -31.53 & -26.56 & $<0.0001$ \\
93 vs. 150 & -25.13 & 0.89 & -27.39 & -22.86 & $<0.0001$ \\
93 vs. 73 & 3.92 & 0.61 & 2.35 & 5.48 & $<0.0001$ \\
\hline
\end{tabular}

The model parameter estimates are interpreted as the mean, $\mathrm{SE}=$ standard error of the mean, $\mathrm{LCI}=$ lower confidence intervals, $\mathrm{UCI}=$ upper confidence intervals, $P$-values are at a significance level of $\alpha=0.05$

Table 4

Results of the two-sample Kolmogorov-Smirnov test comparing the catch size frequency distributions for captured specimens of Clarias gariepinus from the upper Okavango River delta, Botswana and gillnets of different mesh sizes used

\begin{tabular}{ccc}
\hline Mesh size $[\mathrm{mm}]$ & $D$ & $P$-value \\
\hline 118 vs. 150 & 0.73 & $<0.0001$ \\
118 vs. 73 & 0.81 & $<0.0001$ \\
118 vs. 93 & 0.73 & $<0.0001$ \\
150 vs. 73 & 0.88 & $<0.0001$ \\
150 vs. 93 & 0.84 & $<0.0001$ \\
73 vs. 93 & 0.36 & $<0.0001$ \\
\hline
\end{tabular}

$D=$ the Kolmogorov-Smirnov D-statistic; The corresponding $P$-values are at a significance level of $\alpha=0.05$

Table 5

Results of log-linear fits of SELECT to Clarias gariepinus data from the upper Okavango River delta, Botswana

\begin{tabular}{|c|c|c|c|c|}
\hline \multirow{2}{*}{ Model } & \multicolumn{2}{|c|}{ Equal fishing intensity } & \multicolumn{2}{|c|}{ Proportional fishing intensity } \\
\hline & Parameters & Model deviance & Parameters & Model deviance \\
\hline Normal (common spread) & $(\kappa, \sigma)=(0.57,8.93)$ & 245.32 & $(\kappa, \sigma)=(0.57,9.11)$ & 238.94 \\
\hline Normal (Prop. spread) & $\left(\kappa_{1}, \kappa_{2}\right)=(0.58,0.008)$ & 346.81 & $\left(\kappa_{1}, \kappa_{2}\right)=(0.60,0.008)$ & 348.66 \\
\hline Lognormal & $\left(\mu_{1}, \sigma\right)=(3.74,0.16)$ & 276.96 & $\left(\mu_{1}, \sigma\right)=(3.77,0.16)$ & 276.96 \\
\hline Gamma & $(\alpha, \kappa)=(40.92,0.01)$ & 288.65 & $(\alpha, \kappa)=(41.92,0.01)$ & 288.65 \\
\hline
\end{tabular}

The model deviance is the likelihood ratio goodness of fit statistic with 52 degrees of freedom for each model.

46-50 $\mathrm{cm}$ and $51-55 \mathrm{~cm} \mathrm{TL}$, respectively. A large positive residual is apparent for size class of $46-50 \mathrm{~cm}$ TL in the $93 \mathrm{~mm}$ mesh size indicating that this size class has more catch than that predicted by the model.

The modal lengths for the four mesh sizes estimated from the normal fixed spread model under the assumption that fishing intensity is proportional to mesh size are shown in Table 6. Estimated modal lengths were larger than the observed modal lengths for mesh sizes 93, 118, and $150 \mathrm{~mm}$. For the $73 \mathrm{~mm}$ mesh size, the estimated modal length was smaller than the observed modal length from the catch size frequency distribution.

\section{DISCUSSION}

This study showed that the normal fixed spread model provided the best fit for gillnet selectivity in Clarias gariepinus. This is an indication that this species is mainly caught by being gilled or wedged, thus producing a bellshaped relative selectivity curve (Dos Santos et al. 2003). This also means that the proportion of large fish that got entangled in small meshes was insignificant. This is supported by the catch size distributions which showed that there was distinct size selectivity between mesh sizes with mean size increasing for bigger mesh sizes and mean lengths that were significantly different between mesh sizes. 


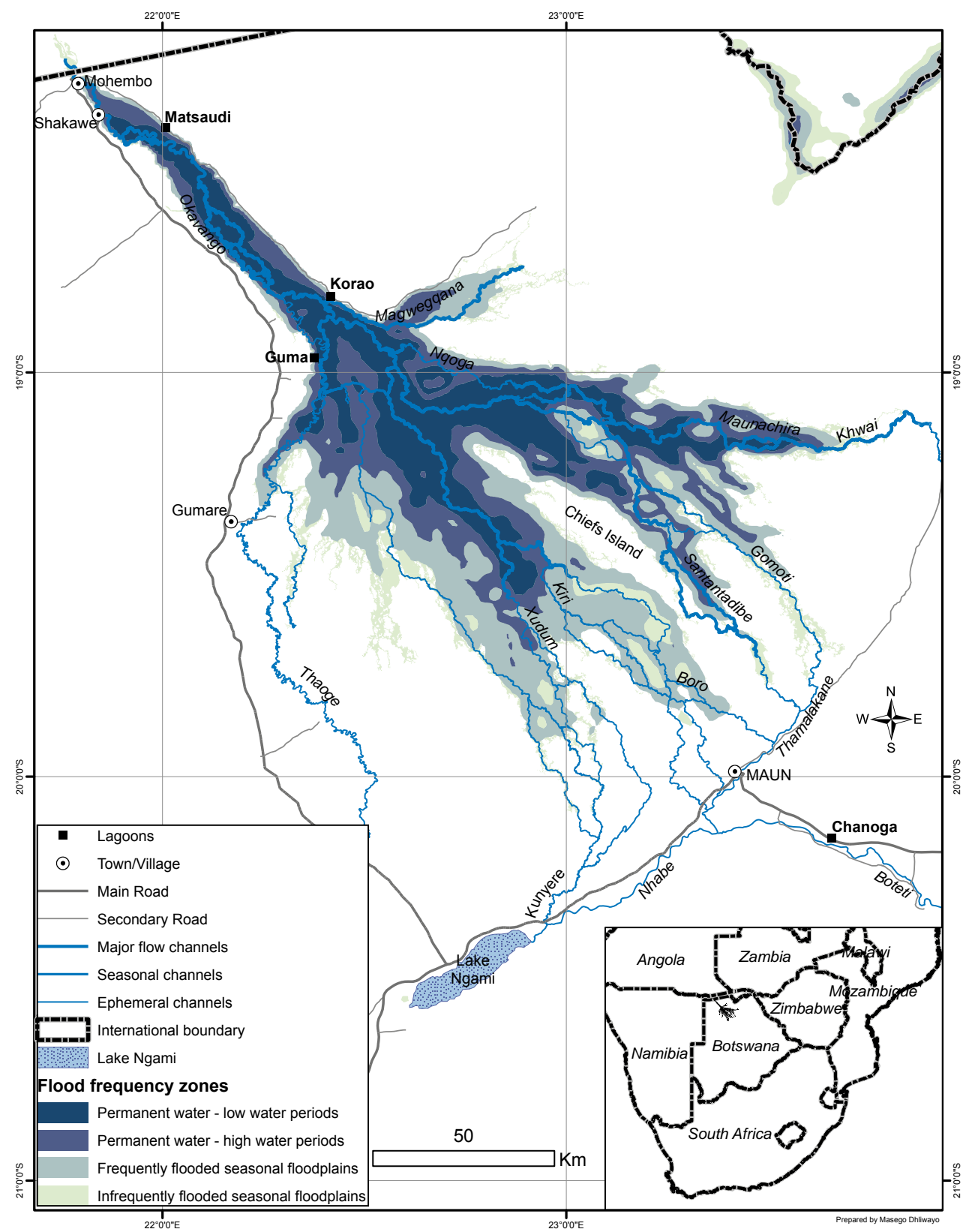

Fig. 1. A map of the Okavango Delta showing the sampling sites; Gillnets were set at Matsaudi Lagoon, Korao Lagoon and Guma Lagoon from the upper Okavango River delta, Botswana

Estimates of modal lengths for Clarias gariepinus caught in gillnets of different mesh sizes

Table 6 from the upper Okavango River delta, Botswana

\begin{tabular}{cccc}
\hline Model & Mesh size $[\mathrm{mm}]$ & Mode $[\mathrm{mm}]$ & SD \\
\hline Normal: fixed spread & 73 & 41.63 & 9.12 \\
& 93 & 53.23 & 8.65 \\
& 118 & 66.35 & 9.50 \\
& 150 & 85.54 & - \\
\hline
\end{tabular}

Estimates were derived only for the normal fixed spread model assuming that fishing intensity is proportional to mesh size; $\mathrm{SD}=\mathrm{standard}$ deviation. 


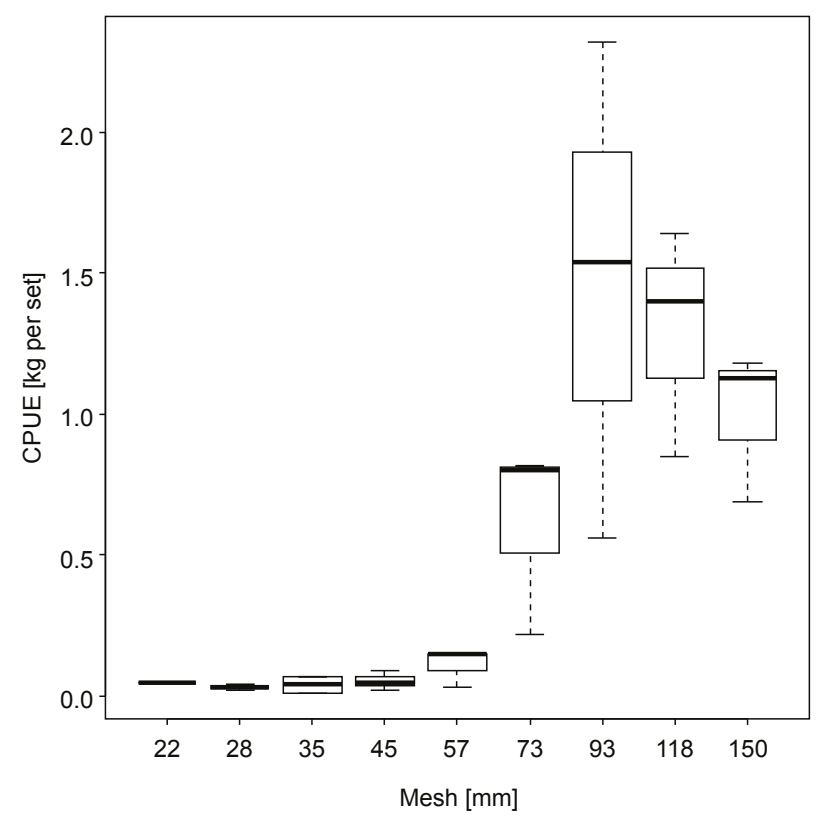

Fig. 2. Catch rates $\left(\mathrm{kg} \cdot \mathrm{panel}^{-1} \cdot \mathrm{set}^{-1}\right)$ of Clarias gariepinus for the different mesh sizes of the brown nets from the upper Okavango River delta, Botswana. Four mesh sizes ( $73 \mathrm{~mm}, 93 \mathrm{~mm}, 118 \mathrm{~mm}$, and $150 \mathrm{~mm}$ ) show marked fishing efficiency with mesh $93 \mathrm{~mm}$ producing the highest catch per set

73

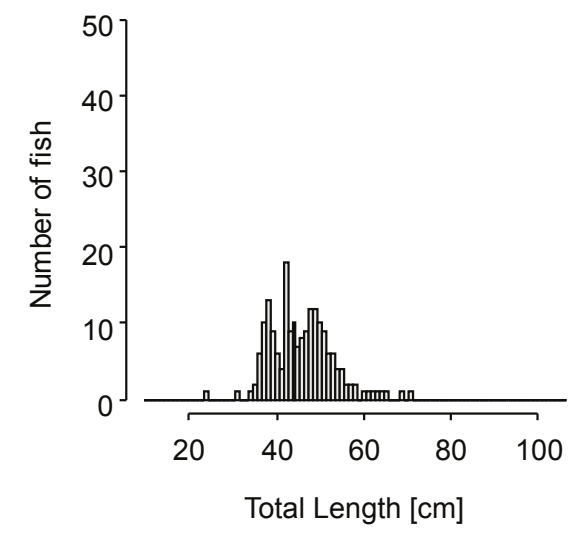

118

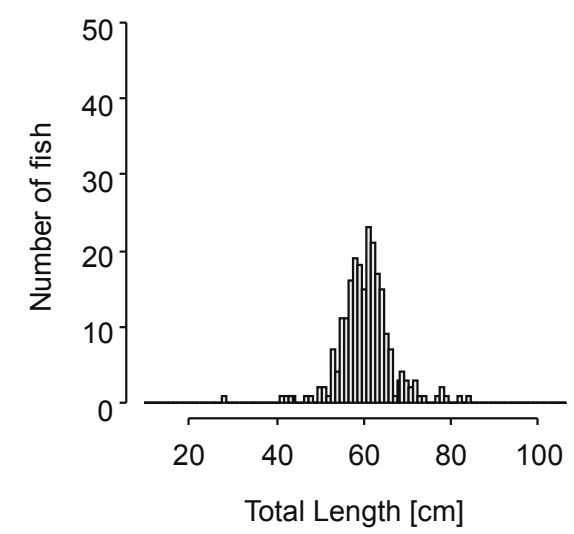

Investigation of the residual plots indicated that all selectivity models demonstrated some bias for the 40-60 cm TL size classes in the $73 \mathrm{~mm}, 93 \mathrm{~mm}$, and $118 \mathrm{~mm}$ net panels. To this end, all models overestimated the numbers of C. gariepinus caught in the $73 \mathrm{~mm}$ and $118 \mathrm{~mm}$ net panels while underestimating catch in the $93 \mathrm{~mm}$ net panel. Baremore et al. (2012) made similar observations for juvenile blacktip sharks, Carcharhinus limbatus (Müller et Henle, 1839) and concluded that overdispersion for the fitted selectivity models was a result of pooling data into $5 \mathrm{~cm}$ bins. This could also be the case for C. gariepinus because data in this study was also grouped into $5 \mathrm{~cm}$ bins. Moreover C. gariepinus often aggregate for communal feeding during the drawdown period in a phenomenon known as pack hunting (Merron 1993). Therefore it is common to catch groups of similar sized fish of this species during this time. This could account for the models underestimation of catch in the $93 \mathrm{~mm}$ mesh size.

The models' overestimation of catch in the $73 \mathrm{~mm}$ and $118 \mathrm{~mm}$ net panels can be attributed to net damage by crocodiles. The Okavango River has a considerable number of crocodiles and the largest size class of these animals feed primarily on fish (Wallace and Leslie 2008). On many occasions crocodiles would normally break the nets when feeding on captured fish since the nets were soaked overnight. This would usually leave large holes on

\section{3}

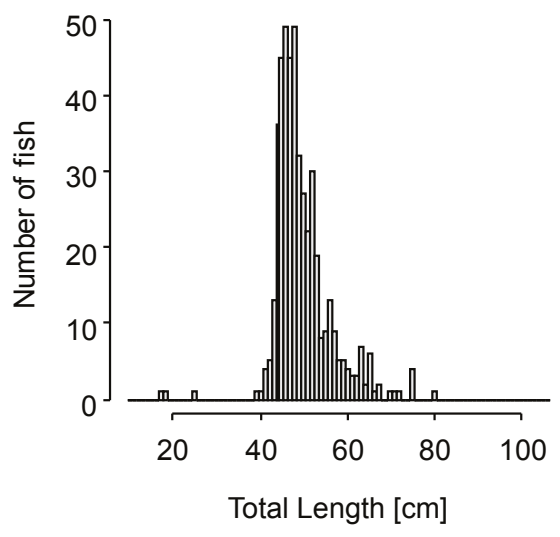

150

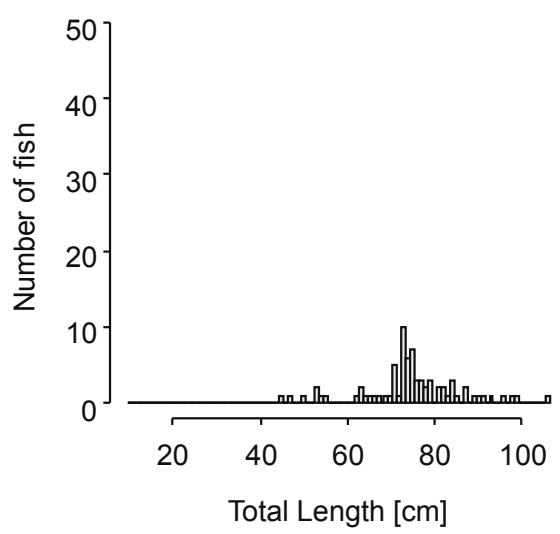

Fig. 3. Observed catch (number of fish per length class) for Clarias gariepinus from the upper Okavango River delta, Botswana, in gillnets with $73 \mathrm{~mm}, 93 \mathrm{~mm}, 118 \mathrm{~mm}$, and $150 \mathrm{~mm}$ mesh sizes 

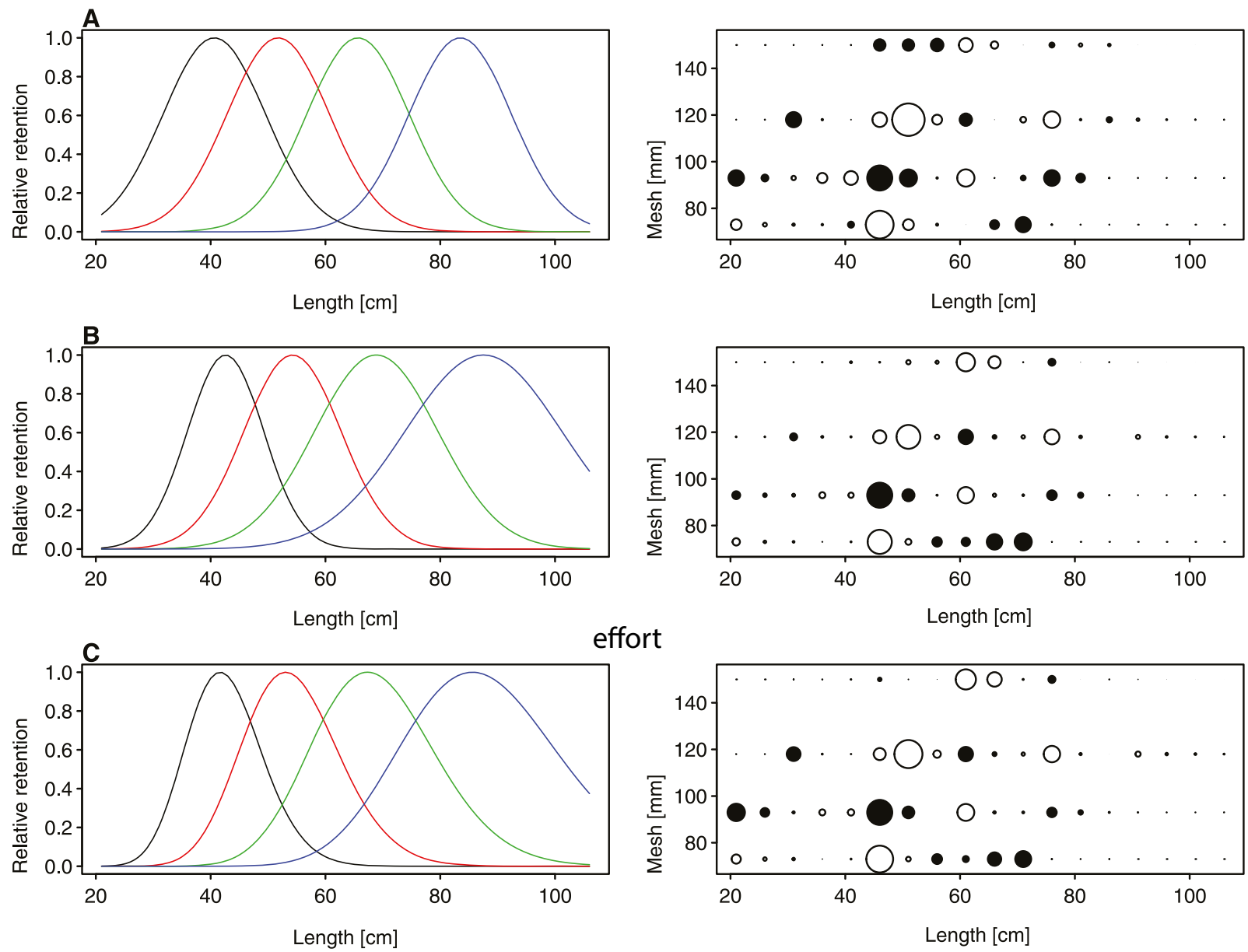

effort
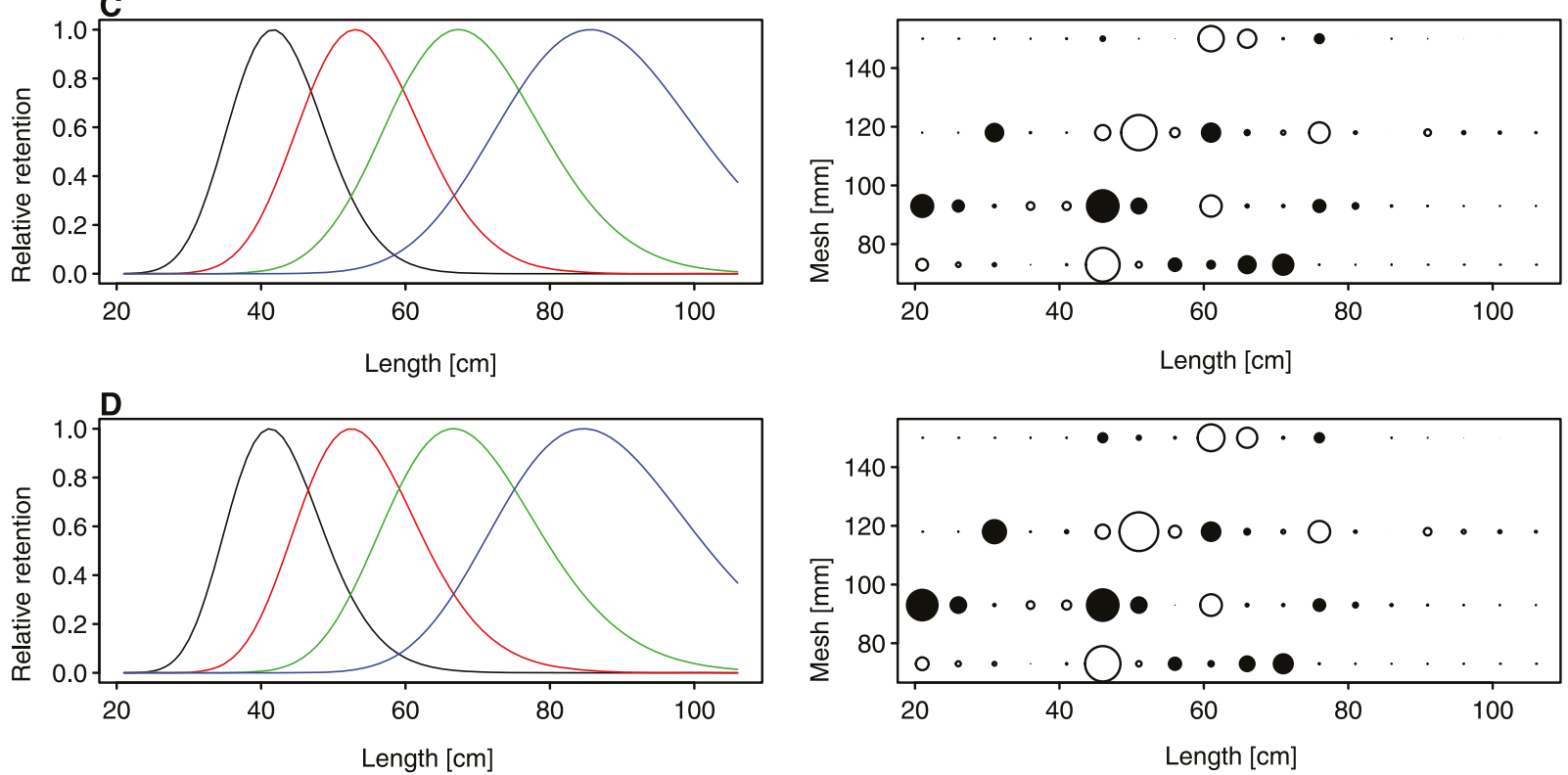

Fig. 4. Gillnet selectivity curves and deviance residuals estimated for Clarias gariepinus from the upper Okavango River delta, Botswana calculated from the normal (fixed) spread (A), normal (proportional spread) (B), lognormal (C), and gamma distributions (D); The curves were fitted under the assumption that fishing intensity is proportional to mesh size; The mesh sizes increase from left to right; The plots on the right are the residuals for the different models with mesh size on the y-axis; Filled circles represent positive residuals and open circles represent negative residuals; The area of the circle is proportional to the square of the residual

the net panels. Panel $118 \mathrm{~mm}$ could have been more susceptible to crocodile attack due to its ability to capture a substantive number of relatively large fish. This could also be an indication that even though panel assemblage was supposed to be random, panels $118 \mathrm{~mm}$ and $73 \mathrm{~mm}$ were tied adjacent to one another during most of the settings, thus making panel $73 \mathrm{~mm}$ equally vulnerable to crocodile attack. Damage on net panels could also result in violation of the geometric similarity assumption which was demonstrated by high model deviances for those models that assumed geometric similarity. Apart from the lack of fit for the 40-60 cm TL size classes, the models generally described the data well with similar sized residual errors and little systematic bias.

The preferred mesh size in the Okavango gillnet fishery is currently $100 \mathrm{~mm}$ (Shipton unpublished*). The estimated size at maturity for Clarias gariepinus in the Upper Okavango Delta is $27.3 \mathrm{~cm}$ TL for females and $36.2 \mathrm{~cm}$ TL for males (Mosepele and Nengu 2003). Therefore the estimated modal lengths for the two mesh sizes (93 and 
$118 \mathrm{~mm}$ ) that are most efficient at capturing C. gariepinus are greater than the estimated size at maturity. Since the $100 \mathrm{~mm}$ mesh size falls between 93 and $118 \mathrm{~mm}$, the current commercial gillnet fishery may not pose any threats to the $C$. gariepinus population.

\section{CONCLUSIONS AND MANAGEMENT RECOM- MENDATIONS}

This study, even though using fishery independent surveys data closely followed the harvesting pattern employed by the commercial gillnet fishery especially with regard to mesh sizes and soaking time. Therefore this study could act as a proxy for estimation of the size structure of the Clarias gariepinus population that is exploited by the commercial gillnet fishery in the Okavango Delta. However, low sample sizes from this study may not be a reflection of the potential catch from the commercial gillnet fishery. This is because the effort used in this study was relatively low (one net setting per station per month) and the nets were multifilament thus making them easy for the fish to see and avoid in the clear Okavango waters. On the other hand, commercial fishers use monofilament gillnets, which are almost invisible to fish, span between $150 \mathrm{~m}$ and $200 \mathrm{~m}$ in length and are set across lagoons and channels.

The fishery appears to be self-regulating because even though there is no mesh size regulation, the preferred mesh size in the fishery $(100 \mathrm{~mm})$ corresponds to high CPUE while capturing fish at lengths larger than maturity. This is also an indication of a healthy stock that is under exploited thus agreeing with Mosepele (unpublished) who found that Maximum Sustainable Yield could not be reached for C. gariepinus in the Okavango Delta. Future studies should aim to conduct fishery dependent selectivity studies in the Lower Okavango Delta to see if selectivity changes with location, gear or target species (Baremore et al. 2012), particularly because recently, studies have suggested the possibility of two distinct populations of $C$. gariepinus between the Upper and Lower Okavango Delta (Bokhutlo et al. 2015).

Indeed, it is crucial to consider selectivity studies for other species, particularly those that are smaller, less hardy and preyed upon by Clarias gariepinus so that they may be included in a multispecies fisheries management plan. Furthermore, the Department of Wildlife and National Parks (DWNP) should continue to carry out experimental fishing surveys with increased effort to obtain substantive sample sizes. Since gillnet panel order and position relative to shore may have an effect on the efficiency of the panels to capture fish, a randomised block design should be used to select panel order so that the effect of panel position and the interaction between panels may be minimised (Wilson and Andrew 1987).

Finally, developing a catfish based gillnet fishery would fall under the current legislation with close monitoring of the size structure, particularly mean length. This kind of monitoring will provide a platform for implementation of adaptive management strategies as the fishery evolves over time. Moreover, there is a need to conduct a comprehensive age-based stock assessment to determine the selection at age for each mesh size, thus establishing those mesh sizes that maximise yield without a high risk of stock collapse.

\section{ACKNOWLEDGEMENTS}

The first author thanks the Department of Wildlife and National Parks for provision of funding that enabled collection of the data used in this study. The assistance of Mothusi Maithamako, Godwin Kenosi, Layton Mmopi, and Aaron Samoxa during field sampling is highly appreciated. We thank G. Glenn Wilson, and Olaf L.F. Weyl for their comments on the earlier version of the manuscript. Masego Dlhiwayo, Oabona Mpudi, and Charles Kabomo assisted with the map and figures.

\section{REFERENCES}

Baremore I.E., Bethea D.M., Andrews K.I. 2012. Gillnet selectivity for juvenile blacktip sharks (Carcharhinus limbatus). Fishery Bulletin 110 (2): 230-241.

Bokhutlo T., Weyl O.L.F., Mosepele K., Wilson G.G. 2015. Age and growth of sharptooth catfish, Clarias gariepinus (Burchell, 1822) (Clariidae), in the Lower Okavango Delta, Botswana. Marine and Freshwater Research 66 (5): 420-428.

DOI: $10.1071 / \mathrm{MF} 13322$

Butterworth D.S., Rademeyer R.A., Brandão A., Geromont H.F., Johnson S.J. 2014. Does selectivity matter? A fisheries management perspective. Fisheries Research 158: 194-204.

DOI: 10.1016/J.FISHRES.2014.02.004

Carlson J.K., Cortés E. 2003. Gillnet selectivity of small coastal sharks off the southeastern United States. Fisheries Research 60 (2): 405-414.

DOI: $10.1016 / \mathrm{S} 0165-7836(02) 00135-2$

Dos Santos M.N., Gaspar M., Monteiro C.C., Erzini K. 2003. Gill net selectivity for European hake Merluccius merluccius from southern Portugal: Implications for fishery management. Fisheries Science 69 (5): 873-882.

DOI: 10.1046/J.1444-2906.2003.00702.X

Hothorn T., Bretz F., Westfall P. 2008. Simultaneous inference in general parametric models. Biometrical Journal 50 (3): 346-363. DOI: 10.1002/BIMJ.200810425

Hovgård H., Lassen H., Madsen N., Poulsen T.M., Wileman D. 1999. Gillnet selectivity for North Sea Atlantic cod (Gadus morhua): Model ambiguity and data quality are related. Canadian Journal of Fisheries and Aquatic Sciences 56 (7): 1307-1316. DOI: 10.1139/F99-070

Hulson P.-J.F., Hanselman D.H. 2014. Tradeoffs between bias, robustness, and common sense when choosing selectivity forms. Fisheries Research 158: 63-73.

DOI: 10.1016/J.FISHRES.2013.12.016 
McCarthy T.S., Bloem A., Larkin P.A. 1998. Observations on the hydrology and geohydrology of the Okavango Delta. South African Journal of Geology 101 (2): 101-117.

Merron G.S. 1993. Pack-hunting in two species of catfish, Clarias gariepinus and C. ngamensis, in the Okavango Delta, Botswana. Journal of Fish Biology 43 (4): 575-584.

DOI: 10.1111/J.1095-8649.1993.TB00440.X

Millar R.B., Fryer R.J. 1999. Estimating the size-selection curves of towed gears, traps, nets and hooks. Reviews in Fish Biology and Fisheries 9 (1): 89-116.

DOI: $10.1023 / \mathrm{A}: 1008838220001$

Millar R.B., Holst R. 1997. Estimation of gillnet and hook selectivity using log-linear models. ICES Journal of Marine Science 54 (3): 471-477.

DOI: 10.1006/JMSC.1996.0196

Mmopelwa G., Mosepele K., Mosepele B., Moleele N., Ngwenya B. 2009. Environmental variability and the fishery dynamics of the Okavango delta, Botswana: The case of subsistence fishing. African Journal of Ecology 47 (Suppl. s1): 119-127.

DOI: $10.1111 /$ J.1365-2028.2008.01058.X

Mosepele K., Nengu S. 2003. Growth, Mortality and length-weight parameters of selected fishes of the Okavango Delta, Botswana. ACP-EU Fisheries Research Report 14: 67-74.
Psuty I., Draganik B., Blady W. 2007. Gillnet selectivity to roach, Rutilus rutilus from the Szczecin Lagoon, Poland. Acta Ichthyologica et Piscatoria 37 (1): 17-23. DOI: 10.3750/AIP2007.37.1.03

Ramberg L., Hancock P., Lindholm M., Meyer T., Ringrose S., Sliva J., Van As J., VanderPost C. 2006. Species diversity of the Okavango Delta, Botswana. Aquatic Science 68 (3): 310-337. DOI: $10.1007 / \mathrm{S} 00027-006-0857-Y$

Richardson T.J., Booth A.J., Weyl O.L.F. 2009. Rapid biological assessment of the fishery potential of Xonxa Dam, near Queestown, South Africa. African Journal of Aquatic Science 34 (1): 87-96.

DOI: 10.2989/AJAS.2009.34.1.9.734

Van der Bank H., Smit N. 2007. Large allozyme variations within populations and isozyme differences between Clarias gariepinus and C. ngamensis from the Okavango Delta, Botswana. African Journal of Aquatic Science 32 (3): 311-315.

DOI: 10.2989/AJAS.2007.32.3.12.311

Wallace K.M., Leslie A. 2008. Diet of the Nile crocodile (Crocodylus niloticus) in the Okavango Delta, Botswana. Journal of Herpetology 42 (2): 361-368. DOI: $10.1670 / 07-1071.1$

Wilson K.H., Andrew J.H. 1987. Influence of gill net hang ratio on the catch of salmon in the Fraser River. Canadian Technical Report on Fisheries and Aquatic Sciences No. 1516.

Received: 4 August 2014

Accepted: 3 March 2015

Published electronically: 30 June 2015 